\title{
Improved Adaptive Neuro-Fuzzy Inference System Based on Particle Swarm Optimization Algorithm for Predicting Labor Productivity
}

\author{
Nehal Elshaboury ${ }^{1}$, Abobakr Al-Sakkaf ${ }^{2,3}$, Ghasan Alfalah ${ }^{4}$ \\ Eslam Mohammed Abdelkader ${ }^{5}$ \\ ${ }^{1}$ Construction and Project Management Research Institute/Housing and Building National Research Centre \\ Giza, Egypt \\ ${ }^{2}$ Department of Architecture \& Environmental Planning/College of Engineering \& Petroleum/Hadhramout University \\ Mukalla, Yemen \\ ${ }^{3}$ Department of Building, Civil and Environmental Engineering/Concordia University \\ Montréal, Canada \\ ${ }^{4}$ Department of Architecture and Building Sciences/King Saud University \\ Riyadh, Saudi Arabia \\ ${ }^{5}$ Structural Engineering Department/Faculty of Engineering/Cairo University \\ Giza, Egypt \\ nehal_ahmed_2014@hotmail.com; abobakr.alsakkaf@concordia.ca; galfalah@ksu.edu.sa; \\ eslam_ahmed1990@hotmail.com
}

\begin{abstract}
Forecasting accurate labor productivity is critical in construction project management because construction projects are labor-intensive. This study predicts labor productivity using an adaptive neuro-fuzzy inference system (ANFIS) trained using particle swarm optimization (PSO) to enhance prediction accuracy. The model is applied to two high-rise buildings in Montreal, Canada. The accuracy of the proposed model is compared to that of the original ANFIS model using root mean square error (RMSE) and fraction of prediction within a factor of two (FACT2). The assessment metrics show that the ANFIS-PSO model (RMSE 0.414 and FACT2 0.053) exhibits better performance than the traditional ANFIS model for formwork labor productivity. It can be concluded that the ANFIS model, coupled with metaheuristic algorithms, can be a valuable decision-making tool for forecasting construction labor productivity in construction projects.
\end{abstract}

Keywords: labor productivity, machine learning, metaheuristic algorithms, hybrid prediction models

\section{Introduction}

The performance of the construction sector is critical in both developed and developing countries. This sector contributes to the gross domestic product and economic development of any country [1-3]. As a result, increasing construction productivity attracts more investment, boosts industry competitiveness, and creates job opportunities [4]. The construction sector is labor-intensive, with labor expenses accounting for 30-60\% of the overall project expenditures [5-6]. Therefore, boosting labor productivity might improve the performance of building projects. However, the construction industry is confronted with several problems, including diminishing productivity growth [7].

Productivity is not used to estimate the cost of resources; rather, it quantifies the relationship between the resources utilized and the product produced [8-10]. In the construction industry, productivity is usually described as the ratio of an amount of output (e.g., money, product, or service) to a unit of resource input (e.g., labor, machines, materials, and money) [11]. Productivity may be quantified at three levels: industry/sector, project, and activity/process. The project productivity level is preferred since it assists construction businesses in identifying areas for improvement [12].

Quantifying and identifying the interdependencies among significant elements is required for modeling construction labor productivity. The current method of predicting productivity rates is based on an estimator's opinion, published productivity data, or previous project data. Personal bias and staff turnover impact the accuracy of depending on estimators' views. The reported productivity figures do not reflect a contractor's performance, but rather the industry's 
average productivity rates [13]. Past project data generally yields the most accurate and trustworthy estimate [1]. As a result, proper modeling of construction labor productivity allows avoiding the subjectivity and irrelevance of the old technique. These models capture the variance in productivity with regard to the influencing input parameters, resulting in successful construction project planning and scheduling [14].

\section{Literature Review}

Artificial intelligence is deemed to be an effective technique for forecasting construction labor productivity. Heravi and Eslamdoost [15] employed a back propagation neural network (BPNN) model to predict labor productivity. When early stopping and Bayesian regularization were compared, Bayesian regularization outperformed early stopping. A sensitivity analysis was also performed to assess the impact of each input element on the prediction performance of the models. El-Gohary et al. [1] applied neural networks to estimate construction labor productivity. To benchmark construction labor productivity, many activation and transfer functions, as well as a wide variety of influencing factors, were used. When compared to standard approaches in the literature, the suggested model produced more accurate findings. Golnaraghi et al. [8] compared the results of BPNN, general regression neural network (GRNN), radial base function neural network (RBFNN), and adaptive neuro-fuzzy inference system (ANFIS) to evaluate labor productivity. According to the results, BPNN outperformed other approaches for predicting labor productivity. Mlybari [16] estimated labor productivity using GRNN, artificial neural networks (ANN), support vector machine (SVM), and multiple additive regression trees (MART). According to the findings, the GRNN model outperformed the other approaches for forecasting labor productivity in concrete pouring and finishing as well as steel fixing. Mohammed Abdelkader et al. [17] compared an ensemble of machine learning models for the sake of estimating loss of productivity as a result of change orders. In the developed model, the loss of productivity was quantified with regards to type of work, its impact, number of change orders, their frequency, average size of change orders and change order hours. The utilized machine learning models encompassed radial basis neural network, generalized regression neural network, cascade forward neural network, Elman neural network, back propagation neural network, multiple linear regression and hybrid particle swarm optimization-liner regression. It was evinced that radial basis neural network surpassed other machine learning models attaining mean absolute percentage error, mean absolute error and root mean square error of $2.44 \%, 0.014$ and 0.027 , respectively.

The application of hybrid intelligent models has recently received a lot of attention to increase model performance [16-19]. Scholars used a combination of techniques to forecast labor productivity. Cheng et al. [20] used an evolutionary fuzzy SVM inference model to forecast productivity loss caused by change orders in building projects. To enhance data quality, many data pre-processing techniques were used, including data cleaning, attribute reduction, and data transformation. Several performance metrics were used to compare the proposed model against ANN, SVM, and evolutionary SVM inference models. The suggested model produced the most accurate and consistent results.

In several instances, the ANFIS model outperformed the ANN model [21-22]. However, it ran into several issues while optimizing the parameters of the membership functions, which had a detrimental influence on prediction accuracy. Meta-heuristics have been widely deployed in the recent years to amplify the search abilities of machine learning models [23-26]. In this regard, the ANFIS model can be improved using metaheuristic methods to enhance prediction outcomes [27-28]. In this regard, the primary goal of this study is to assess the effectiveness of an ANFIS model trained using a particle swarm optimization (PSO) algorithm for forecasting formwork labor productivity. Two high-rise buildings in Montreal, Canada are utilized to test and validate the suggested models. The results of the improved ANFIS model are compared to the results of a conventional ANFIS model using two performance measures. The suggested hybrid model can assess and predict labor productivity, resulting in more accurate and realistic predictions for building projects.

\section{Materials and methods}

\subsection{Adaptive neuro-fuzzy inference system}

The adaptive neuro-fuzzy inference system (ANFIS) combines the capabilities of neural networks with fuzzy logic to automatically create the fuzzy if-then rule [29-30]. The ANFIS structure is made up of five levels. The first layer fuzzifies the input parameters, while the second layer calculates the firing strength of the rules. The third layer 
normalizes the rules' firing strength. The fourth layer distributes the rule outputs, which are aggregated in the fifth layer to determine the system output. The fuzzy inference system may be generated using three methods: grid partitioning, subtractive clustering, and fuzzy c-means clustering. The fuzzy c-means clustering approach is employed in this study because it produced the most accurate findings when compared to other methods [31].

\subsection{Particle swarm optimization algorithm}

Particle swarm optimization (PSO) was developed by Eberhart and Kennedy [32] to mimic the behavior of birds and fish when looking for food. The goal function is defined as the particle's proximity to the optimal solution. Each particle's current position, best position, and velocity are all recorded. Initial locations and velocities are allocated to the particles. When a new better position is discovered, the particle's best position is automatically changed. In each cycle, the global best position is calculated by averaging the particle best locations. Every iteration, the particle location is modified by evaluating randomized values in various directions [33]. To avoid early or late convergence, this procedure is continued until a termination condition is reached. The global solution is the current position of the best particle in the last iteration. Particle swarm optimization algorithm is an efficient meta-heuristic that have been successfully implemented in wide range of civil engineering applications such as corrosion assessment of bridge decks [34], forecasting bearing capacity of piles [35], spatial land-use allocation [36] and solving prestess modes of cable-strut structures [37].

\subsection{ANFIS model coupled with metaheuristic algorithms}

The PSO method is used in this study to estimate the parameters of the membership function in the ANFIS model. Using the input and target data, the fuzzy inference system is built. The ANFIS model output is calculated, and error objective functions are minimized using Eq. (1) [38]. When the best output is produced, the optimization process comes to an end. Otherwise, the optimization of the membership function is repeated.

$$
\text { Objective function }=\min (\mathrm{RMSE})=\min \left(\sqrt{\operatorname{mean}(\mathrm{e})^{2}}\right)=\min \left(\sqrt{\operatorname{mean}(\mathrm{t}-\mathrm{y})^{2}}\right)
$$

Where; $t$ represents the target data, $y$ represents the output data, and e represents the error objective function to be minimized.

\section{Performance metrics}

Two performance assessment criteria are used to assess the modeling performance of the classical and hybrid intelligent models. These measures are as follows: root mean square error (RMSE) and fraction of prediction within a factor of two (FACT2).

\subsection{Root mean square error}

According to Eq. (2), the root mean squared error (RMSE) indicates the distance between the observed and predicted values. It has a value between 0 and infinity. It should be noted that a lower RMSE value implies a better model absolute fit [39-40].

$$
\text { RMSE }=\sqrt{\frac{1}{n} \sum_{i=1}^{n}\left(o_{i}-p_{i}\right)^{2}}
$$

Where; $o_{i}$ and $p_{i}$ represent the actual and simulated values, respectively and $n$ is the number of data points.

\subsection{Fraction of prediction within a factor of two}

The fraction of prediction within a factor of two (FACT2) is the percentage of predicted values that are within a factor of two of the expected values, as calculated by Eq. (3). The closer FACT2 is to 1, the better the model performs [41].

$$
\text { FACT2 }=\frac{1}{n-1} \sum_{i=1}^{n}\left(\frac{o_{i}-\overline{o_{1}}}{\sigma_{o}}\right)\left(\frac{p_{i}-\overline{p_{1}}}{\sigma_{p}}\right), 0.5 \leq \frac{o_{i}}{p_{i}} \leq 2
$$

Where; $\overline{o_{1}}$ denotes the mean actual value, $\overline{p_{1}}$ denotes the mean simulated value, $\sigma_{o}$ denotes the standard deviation of the actual values, and $\sigma_{\mathrm{p}}$ denotes the standard deviation of the simulated values.

\section{Model development}


The framework of applying standalone and hybrid machine learning models for forecasting the labor productivity of formwork assembly is presented in this section. The framework, as illustrated in Fig. 1, consists of the following steps: 1) establishing the input and output parameters from the available dataset, 2) dividing the data into training and testing phases, 3) running the prediction models, 4) forecasting output productivity, 5) calibrating and comparing models using performance assessment measures, and 6) recommending the optimal prediction model.

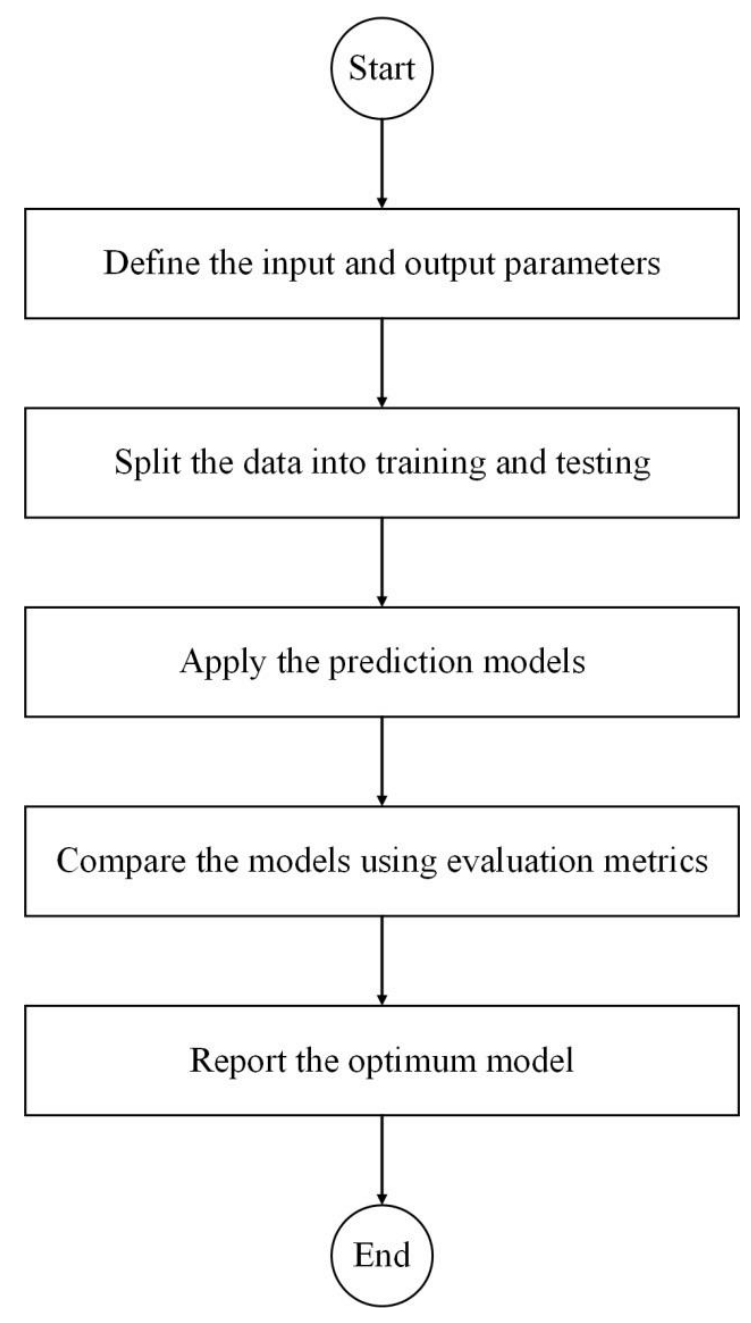

Fig. 1: Flowchart for predicting formwork labor productivity

\section{Case study}

Over eighteen months, data on labor productivity was collected from two high-rise buildings in Montreal, Canada [42]. The first structure was built of concrete and had a flat slab construction system. It had 17 floors and a surface area of $68,000 \mathrm{~m} 2$, and it took three years to build. The second structure employed the same structural system as the first. These projects include a total of 221 data points for formwork activity. The data includes project, crew, and weather-related parameters. Data related to job type and procedure, as well as floor level, are classed as project data, whereas gang size and labor percentage belong to crew data. The factors utilized in the weather category include temperature, humidity, precipitation, and wind speed. 
The aforementioned factors must be taken into account since they affect daily work productivity. Table 1 depicts additional statistical parameters for the nine variables. It should be noted that the work type includes three forms of formwork: slabs (1), walls (2), and columns (3). Furthermore, the work approach incorporates built-in place (1) and flying forms (2). The number of floors is referred to as the floor level. The gang size in the crew category refers to the number of people in a crew. In addition, the labor percentage is the ratio of labor size to gang size. Temperature, humidity, and wind speed are measured in Celsius (oC), percentage (\%), and kilometers per hour, respectively. Furthermore, precipitation can be classified as no precipitation (0), light rain (1), snow (2), or rain (3).

Table 1: Statistical parameters of input and output factors

\begin{tabular}{|c|c|c|c|c|c|}
\hline Variable & Min & Max & Mean & Median & Standard deviation \\
\hline Work type & 1.00 & 3.00 & 1.43 & 1.00 & 0.51 \\
\hline Work method & 1.00 & 2.00 & 1.44 & 1.00 & 0.50 \\
\hline Floor level & 1.00 & 17.00 & 11.38 & 12.00 & 3.75 \\
\hline Gang size & 8.00 & 24.00 & 16.03 & 18.00 & 5.07 \\
\hline Labor percentage & 29.00 & 47.00 & 35.49 & 36.00 & 3.79 \\
\hline Temperature & -26.00 & 25.00 & 4.08 & 3.00 & 12.03 \\
\hline Humidity & 18.00 & 97.00 & 66.34 & 67.00 & 15.67 \\
\hline Precipitation & 0.00 & 3.00 & 0.28 & 0.00 & 0.60 \\
\hline Wind speed & 3.00 & 43.00 & 15.42 & 14.00 & 8.46 \\
\hline Productivity & 0.82 & 2.53 & 1.57 & 1.51 & 0.35 \\
\hline
\end{tabular}

\section{Results and discussion}

The effectiveness of the ANFIS and ANFIS-PSO models for forecasting formwork labor productivity is investigated in this study. To anticipate worker productivity in two high-rise buildings in Montreal, Canada, the traditional ANFIS model is used as the benchmark model. The dataset is divided into two parts: 80 percent for training and 20 percent for testing. For ANFIS, the number of clusters is limited to 15, with a maximum of 200 epochs and iterations. The starting step size, drop rate of step size, and rise rate of step size are 0.01, 0.9, and 1.1, respectively. The following are the settings of the PSO meta-heuristic algorithm: maximum iteration= 1000, population size $=100$, inertia weight $=1$, and personal/global learning coefficient $=2$. To create the machine learning models, the code is created in MATLAB R2015a.

Fig. 2 depicts a comparison between simulated and actual labor productivity estimates. Table 2 summarizes the performance of the machine learning models using two distinct metrics (RMSE and FACT2). These measures assess whether the trend of the model outputs corresponds to or deviates from the real estimate. The RMSE of the conventional ANFIS model (RMSE = 0.537) is quite large, as seen in Table 2. (i.e., above 0.50). This indicates the model's inability to replicate actual estimates. As a result, there is a need to create a model that can be utilized to properly estimate labor productivity. To address the constraints of the traditional ANFIS model, an ANFIS-PSO model is presented in this aspect. When comparing the suggested ANFIS-PSO model to the conventional ANFIS model, the RMSE and FACT2 values show a significant improvement. As a result, the outputs of the hybrid model correspond to actual production. 

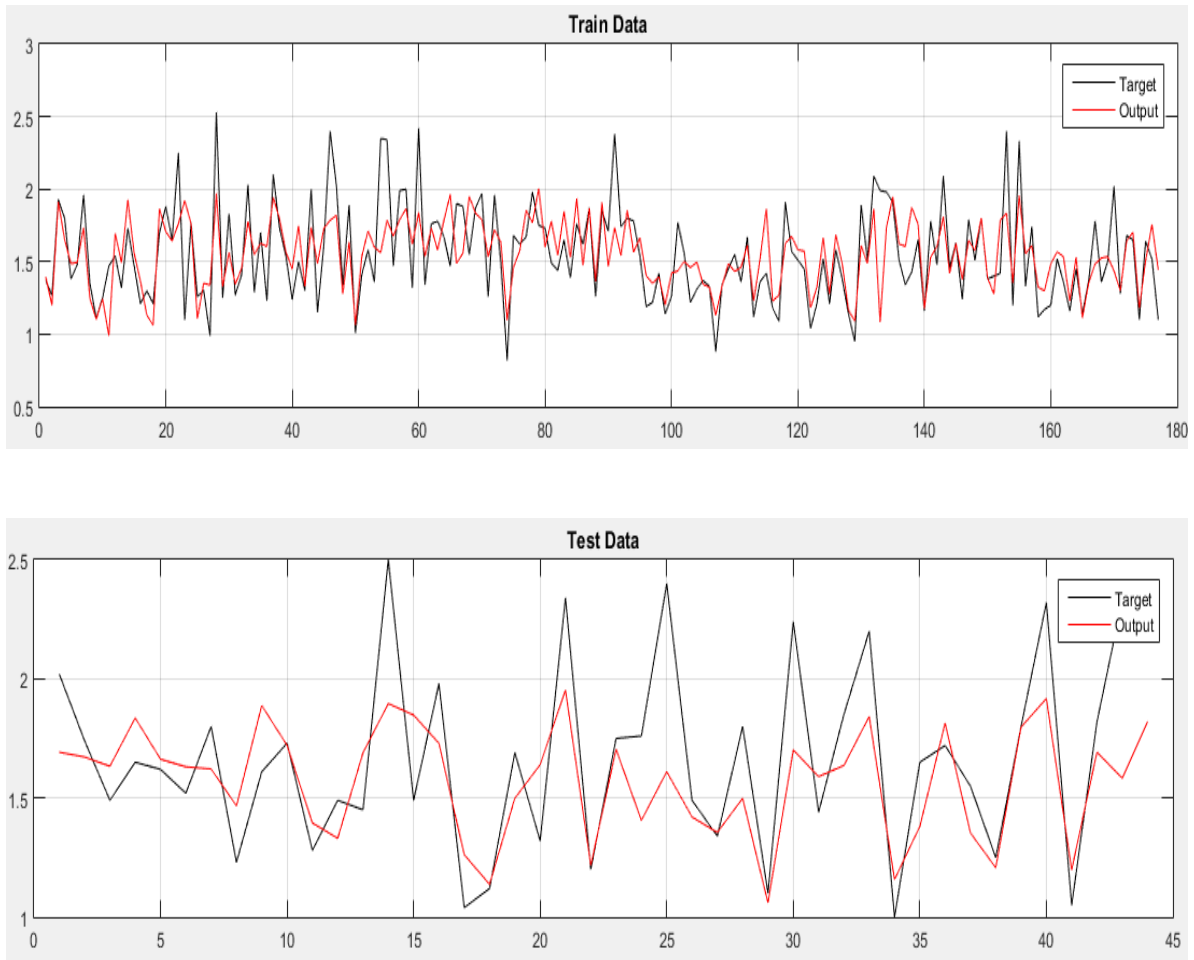

Fig. 2: Comparison of the actual and anticipated labor productivity during the training and testing phases

Table 2: Comparative analysis of machine learning models

\begin{tabular}{|c|c|c|}
\hline \multirow{2}{*}{ Performance metric } & \multicolumn{2}{|c|}{ Machine learning model } \\
\cline { 2 - 3 } & Classical ANFIS model & ANFIS-PSO model \\
\hline RMSE & 0.537 & 0.414 \\
\hline FACT2 & 0.040 & 0.053 \\
\hline
\end{tabular}

\section{Conclusion}

This study presented a forecasting model for labor productivity using the adaptive neuro-fuzzy inference system (ANFIS) coupled with particle swarm optimization (PSO). To assess the effectiveness of the suggested models, historical data from two high-rise structures were collected. Eighty percent of the data was utilized to train the models, while the remaining twenty percent was used to test and validate the models. As input parameters for the models, nine factors related to the project, crew, and weather conditions were chosen. Using root mean square error (RMSE) and fraction of prediction within a factor of two (FACT2) metrics, the suggested hybrid model was compared to the conventional ANFIS model. The findings revealed that the ANFIS-PSO model $(\mathrm{RMSE}=0.414$ and FACT2 $=0.053)$ improved the performance indices when compared to the conventional ANFIS model $(\mathrm{RMSE}=0.537$ and FACT2 $=0.040)$. As a result, the hybrid ANFIS model amalgamated with particle swarm optimizer can be stand as an improved decision-making plattform for predicting formwork labor productivity. 


\section{References}

[1] El-Gohary KM, Aziz RF, Abdel-Khalek HA (2017) Engineering approach using ANN to improve and predict construction labor productivity under different influences. Journal of Construction Engineering and Management 143(8):1-10.

[2] Dixit S, Mandal SN, Thanikal JV, Saurabh K (2019) Evolution of studies in construction productivity: A systematic literature review (2006-2017). Ain Shams Engineering Journal 10(3):555-564.

[3] Dixit S, Mandal SN, Sawhney A, Singh S (2017) Relationship between skill development and productivity in construction sector: a literature review. International Journal of Civil Engineering and Technology 8(8):649-665.

[4] Duncan JR (2002) Innovation in the building sector: Trends and new technologies. In: technical conference of the institution of professional engineers of New Zealand, Building Research Association of New Zealand, Wellington, New Zealand.

[5] Gomar JE, Haas CT, Morton DP (2002) Assignment and allocation optimization of partially multiskilled workforce. Journal of Construction Engineering and Management 128(2):103-109.

[6] Hanna AS, Peterson P, Lee M (2002) Benchmarking productivity indicators for electrical/mechanical projects. Journal of Construction Engineering and Management 128(4):331-337.

[7] Allen SG. (1985) Why construction industry productivity is declining. The Review of Economics and Statistics 67(4):661-669.

[8] Golnaraghi S, Zangenehmadar Z, Moselhi O, Alkass S (2019) Application of artificial neural network(s) in predicting formwork labor productivity. Advances in Civil Engineering 2019:1-11.

[9] Hanna AS (2003) Effectiveness of innovative crew scheduling. Construction Industry Institute, Austin, United States.

[10] El-Batreek AH, Ezeldin AS, Elbarkouky MMG (2013) A framework for construction labor productivity improvement in Egypt. In: 2013 architectural engineering conference, ASCE, Reston, United States.

[11] Durdyev S, Ismail S, Kandymov N (2018) Structural equation model of the factors affecting construction labor productivity. Journal of Construction Engineering and Management 144(4):1-11.

[12] Abdel-Wahab M, Vogl B (2011) Trends of productivity growth in the construction industry across Europe, US and Japan. Construction management and economics 29(6):635-644.

[13] Thomas HR (2010) Quantification of losses of labor efficiencies: Innovations in and improvements to the measured mile. Journal of Legal Affairs and Dispute Resolution in Engineering and Construction 2(2):106-112.

[14] Song L, AbouRizk SM (2008) Measuring and modeling labor productivity using historical data. Journal of Construction Engineering and Management 134(10):786-794.

[15] Heravi G, Eslamdoost E (2015) Applying artificial neural networks for measuring and predicting construction labor productivity. Journal of Construction Engineering and Management 141(10):1-11.

[16] Mlybari EA (2020) Application of soft computing techniques to predict construction labor productivity in Saudi Arabia. International Journal of GEOMATE 19(71):203-210.

[17] Mohammed Abdelkader, E., El-kabalawy, M., Assad, A., Al-Sakkaf, A., and Elshaboury, N. (2020). An Extensive Machine Learning-based Comparative Analysis for Mimicking Loss of Productivity as a Result of Change Orders. The Journal of Scientific and Engineering Research, 7(12): 81-93.

[18] Moazenzadeh R, Mohammadi B, Shamshirband S, Chau KW (2018) Coupling a firefly algorithm with support vector regression to predict evaporation in northern Iran. Engineering Applications of Computational Fluid Mechanics 12(1):584-597.

[19] Aghelpour P, Mohammadi B, Biazar SM (2019) Long-term monthly average temperature forecasting in some climate types of Iran, using the models SARIMA, SVR, and SVR-FA. Theoretical and Applied Climatology 138:14711480 . 
[20] Cheng M, Wibowo DK, Prayogo D, Roy AF (2015) Predicting productivity loss caused by change orders using the evolutionary fuzzy support vector machine inference model. Journal of Civil Engineering and Management 21(7):881-892.

[21] Masoudi S, Sima M, Tolouei-Rad M (2018) Comparative study of ANN and ANFIS models for predicting temperature in machining. Journal of Engineering Science and Technology 13(1):211-225.

[22] Gill J, Singh J, Ohunakin OS, Adelekan DS, Atiba OE, Nkiko MO, Atayero AA (2020) Adaptive neuro-fuzzy inference system (ANFIS) approach for the irreversibility analysis of a domestic refrigerator system using LPG/TiO 2 nanolubricant. Energy Reports 6:1405-1417

[23] Mohammed Abdelkader, E., Marzouk, M. and Zayed, T. (2020). A self-adaptive exhaustive search optimizationbased method for restoration of bridge defects images. International Journal of Machine Learning and Cybernetics, $11,165-1716$.

[24] Li, Y., Jia, M., Han, X., \& Bai, X. S. (2021). Towards a comprehensive optimization of engine efficiency and emissions by coupling artificial neural network (ANN) with genetic algorithm (GA). Energy, 225, 1-13.

[25] Mohammed Abdelkader, E., Moselhi, O., Marzouk, M. and Zayed, T. (2021). A Grey Wolf Optimization-Based Method for Detection and Evaluation of Scaling In Reinforced Concrete Bridges, International Journal of Information Technology and Decision Making, 1-54.

[26] Mohammed Abdelkader, E., Moselhi, O., Marzouk, M. and Zayed, T. (2021). An Integrative Evolutionary-based Method for Modeling and Optimizing Resource Allocation of Bridge Deck Replacement Projects, Journal of Construction Engineering and Management, 147(9), 1-23.

[27] Varnamkhasti MJ (2013) A hybrid of adaptive neuro-fuzzy inference system and genetic algorithm. Journal of Intelligent \& Fuzzy Systems 25(3):793-796.

[28] Mohammadi B, Linh NT, Pham QB, Ahmed AN, Vojteková J, Guan Y, Abba SI, El-Shafie A (2020) Adaptive neuro-fuzzy inference system coupled with shuffled frog leaping algorithm for predicting river streamflow time series. Hydrological Sciences Journal 65(10):1738-1751.

[29] Aghdam IN, Varzandeh MHM, Pradhan B (2016) Landslide susceptibility mapping using an ensemble statistical index (Wi) and adaptive neuro-fuzzy inference system (ANFIS) model at Alborz Mountains (Iran). Environmental Earth Sciences 75:553.

[30] Jang JS (1993) ANFIS: adaptive-network-based fuzzy inference system. IEEE transactions on systems, man, and cybernetics 23:665-685.

[31] A. B. Goktepe, S. Altun and A. Sezer, Soil clustering by fuzzy c-means algorithm, Advances in Engineering Software, 36 (2005) 691-698

[32] Eberhart RC, Kennedy J (1995) A new optimizer using particle swarm theory. In: 6th international symposium on micro machine and human science, IEEE, Nagoya, Japan.

[33] Shi Y, Eberhart R (1998) Parameter selection in particle swarm optimization. In: International conference on evolutionary programming, Springer-Verlag, London, United Kingdom.

[34] Mohammed Abdelkader, E., Marzouk, M., and Zayed, T. (2019). An Optimization-Based Methodology for the Definition of Amplitude Thresholds of the Ground Penetrating. Soft Computing, 23:12063-12086.

[35] Wang, B., Moayedi, H., Nguyen, H., Foong, L. K., \& Rashid, A. S. A. (2020). Feasibility of a novel predictive technique based on artificial neural network optimized with particle swarm optimization estimating pullout bearing capacity of helical piles, Engineering with Computers, 36(4), 1-10.

[36] Li, F., Gong, Y., Cai, L., Sun, C., Chen, Y., Liu, Y., \& Jiang, P. (2018). Sustainable land-use allocation: A multiobjective particle swarm optimization model and application in Changzhou, China. Journal of Urban Planning and Development, 144(2):1-10.

[37] Chen, Y., Yan, J., Sareh, P., \& Feng, J. (2020). Feasible Prestress Modes for Cable-Strut Structures with Multiple Self-Stress States Using Particle Swarm Optimization. Journal of Computing in Civil Engineering, 34(3):1-10.

[38] Termeh SV, Khosravi K, Sartaj M, Keesstra SD, Tsai FT, Dijksma R, Pham BT (2019) Optimization of an adaptive neuro-fuzzy inference system for groundwater potential mapping. Hydrogeology Journal 27(7):2511-2534. 
[39] Elshaboury N, Marzouk M (2020) Comparing machine learning models for predicting water pipelines condition. In: 2020 2nd novel intelligent and leading emerging sciences conference (NILES), IEEE, Giza, Egypt.

[40] Mohammed Abdelkader, E., Moselhi, O., Marzouk, M. and Zayed, T. (2020). Entropy-Based Automated Method for Detection and Assessment of Spalling Severities in Reinforced Concrete Bridges, Journal of Performance of Constructed Facilities, 35(1):1-25.

[41] Sayegh AS, Munir S, Habeebullah TM (2014) Comparing the performance of statistical models for predicting PM10 concentrations. Aerosol and Air Quality Research 14(3):653-665.

[42] Khan ZU (2005) Modeling and parameter ranking of construction labor productivity. Dissertation, Concordia University. 